Aim of the study: The evaluation of quality of life during image-guided radiotherapy (IGRT) in patients with prostate cancer.

Materials and methods: The study consisted of 180 prostate cancer patients treated with radical radiotherapy (IGRT). The patients were irradiated using conformal or dynamic techniques with 2 Gy fractionation doses to a total dose of $76 \mathrm{~Gy}$. Patients in the high-risk group (41\%) were also irradiated to the pelvic lymph nodes. Quality of life was assessed with EORTC questionnaires: general QLQ-C30 and prostate-specific module QLQ-PR25, which were filled in by patients before and upon completion of radiotherapy. A change of $\geq 10$ points in a linearised scale (0-100) was considered clinically significant.

Results: Global quality of life decreased slightly during radiotherapy (from 61 to 57 points), but from the clinical point of view, likewise most of the other quality of life parameters remained stable. In the general module (QLQ-C30) only diarrhoea changed in a clinically relevant way, i.e. by 10 points (from 10 to 20 points), which was mainly observed in patients with elective pelvic irradiation (increase of 18 points, from 10 to 28 points). In the prostate-specific module (QLQ-PR25) only urinary symptoms changed significantly, i.e. by 13 points (from 24 to 37 points).

Conclusions: The quality of life in patients with prostate cancer does not change in a clinically significant way during radiotherapy, which corroborates good treatment tolerance. Increased urinary symptoms and, in the case of pelvic irradiation, also increased diarrhoea have a negative impact on symptom-related quality of life.

Key words: prostate cancer, quality of life, radiotherapy, IGRT.

Contemp Oncol (Pozn) 2014; 18 (4): 285-289 DOI: $10.5114 /$ wo.2014.44097

\section{Quality of life in patients with prostate cancer treated with radical image-guided radiotherapy}

\author{
Wojciech Majewski ${ }^{1}$, Kamil Tabor ${ }^{2}$, Elżbieta Prokop ${ }^{2}$, Roland Kulik ${ }^{3}$
}

1Department of Radiotherapy, Maria Skłodowska-Curie Memorial Cancer Centre and Institute of Oncology, Gliwice Branch, Poland

${ }^{2}$ Doctoral Degree Programme to Medical University of Silesia, Faculty of Medicine and Division of Medical Dentistry in Zabrze, Poland

${ }^{3}$ Department of Radiotherapy and Brachytherapy Planning, Maria Skłodowska-Curie Memorial Cancer Centre and Institute of Oncology, Gliwice Branch, Poland

\section{Introduction}

The progress that has been made during the last decade in modern radiotherapy has resulted in improved treatment tolerance and reduced risk of complications. This was possible through the implementation of strictly conformal, dynamic irradiation techniques and improvements in the precision and reproducibility of radiotherapy using daily verification and correction of patient alignment (IGRT-Image Guided Radiotherapy) [1]. It is estimated that the 15-year survival rate in patients with prostate cancer after radiotherapy reaches $85 \%$ in stage $\mathrm{T} 1$, while stage $\mathrm{T} 2$ and $\mathrm{T} 3$ are, respectively, 65-68\% and $44-75 \%$ [2], and presumably the most recent results of modern radiotherapy are even better. With such a high long-term survival expectancy, an increasingly important criterion for the choice of treatment may be its tolerance. Beside the physician's evaluation of radiation toxicity, the subjective assessment of the quality of life made by the patient has become an important aspect in the assessment of tolerance in modern radiotherapy. Specially designed questionnaires, based on a set of questions covering the most important aspects of everyday life and side effects, provide a comprehensive estimation of the patient's quality of life. In the majority of articles dealing with this issue in prostate cancer radiotherapy, quality of life seems to be stable or only slightly decreased after treatment; however, patients sometimes report a decline in some aspects of daily life, such as bowel or sexual function [3-10]. Most of the published papers on quality of life deal with long-term effects, although the evaluation of patients' short-term tolerance to the treatment is also relevant. The purpose of this work is to analyse and assess the changes in quality of life on the basis of questionnaires (QLQ-C30 and QLQ-PR25) in patients with prostate cancer during radical high-dosage image-guided radiotherapy (IGRT).

\section{Material and methods}

\section{Patient characteristics}

The prospective study consisted of 180 patients (mean age 69 years) with prostate cancer treated with high-dosage radiotherapy at the Department of Radiotherapy, Institute of Oncology, Gliwice in 2008-2011. All of them were consecutive patients treated by the same physician (W.M.). Before the beginning of radiation therapy, each patient was staged based on digital rectal examination, X-ray, computed tomography, transrectal ultrasound, Gleason histological scale and the highest concentration of PSA. The clinical characteristics are presented in Table 1. 
Table 1. Clinical characteristics of the study group

\begin{tabular}{|c|c|}
\hline Clinical parameter & $\begin{array}{c}\text { Number of } \\
\text { patients (\%) }\end{array}$ \\
\hline \multicolumn{2}{|l|}{ T-stage according to the TNM scale } \\
\hline T1c & $75(42 \%)$ \\
\hline $\mathrm{T} 2 \mathrm{a}$ & $36(20 \%)$ \\
\hline $\mathrm{T} 2 \mathrm{~b}$ & $28(16 \%)$ \\
\hline $\mathrm{T} 2 \mathrm{C}$ & $16(9 \%)$ \\
\hline T3 & $21(12 \%)$ \\
\hline $\mathrm{T} 4$ & $4(2 \%)$ \\
\hline \multicolumn{2}{|l|}{ Gleason score } \\
\hline$\leq 6$ & $99(55 \%)$ \\
\hline 7 & $55(31 \%)$ \\
\hline$\geq 8$ & $26(14 \%)$ \\
\hline \multicolumn{2}{|l|}{$\begin{array}{l}\text { Highest serum pre-treatment PSA } \\
\text { concentration }\end{array}$} \\
\hline$<10 \mathrm{ng} / \mathrm{ml}$ & $60(33 \%)$ \\
\hline $10-20 \mathrm{ng} / \mathrm{ml}$ & $60(33 \%)$ \\
\hline$>20 \mathrm{ng} / \mathrm{ml}$ & $60(33 \%)$ \\
\hline \multicolumn{2}{|l|}{ Neoadjuvant hormonal treatment } \\
\hline No hormonal treatment & $22(12 \%)$ \\
\hline Maximum androgen blockade & $114(63 \%)$ \\
\hline LHRH analogue only & $45(25 \%)$ \\
\hline \multicolumn{2}{|l|}{ IGRT verification (all 2D-2D KV) } \\
\hline Pelvic bones & $89(49 \%)$ \\
\hline Implanted fiducial & $91(51 \%)$ \\
\hline
\end{tabular}

Then, according to D'Amico's proposal [11], the patients were divided into risk groups: 106 patients (59\%) were in the low- or intermediate-risk group, and 74 patients (41\%) were in the high-risk group.

All patients were irradiated with dose per fraction of 2 Gy to a total dose of 76 Gy, with daily image-guided verification using a 2D KV-KV system. Positioning of the patient was based on pelvic bone markers or a fiducial marker implanted in the prostate gland (GoldAnchor ${ }^{\mathrm{TM}}$ ). In the high-risk group, pelvic lymph nodes were irradiated at the first stage to a total dose of 44 Gy. Conformal techniques were used in 28 patients (15\%) and dynamic techniques in 152 patients (85\%).

In about $90 \%$ of patients, hormonal treatment was introduced by a referring urologist before radiotherapy. It was used in all patients in the intermediate- and high-risk group, and in some patients in the low-risk group. Mean duration time of hormonal treatment was $7 \pm 10$ months before radiation therapy.

\section{Methods}

Quantitative evaluation of the patients' quality of life was performed using EORTC questionnaires: general QLQ-C30 and specific for prostate cancer QLQ-PR25 [12, 13].

The QLQ-C30 questionnaire consisted of a set of 30 questions:

- 5 scales describing functioning (fulfilling social roles, physical functioning, cognitive functioning, and emotional and social functioning);
- 9 scales or single questions about symptoms (fatigue, pain, nausea and vomiting, constipation, diarrhoea, shortness of breath, sleeplessness, loss of appetite and financial problems);

- 1 scale assessing global health status/quality of life.

The QLQ-PR25 questionnaire consisted of a set of 25 questions:

- 2 functional scales (activity and sexual function);

- 4 symptomatic scales (symptoms of urinary tract, intestinal symptoms, urinary incontinence and symptoms associated with hormonal therapy).

The questions were arranged according to the same four-point pattern ("never", "sometimes", "often" and "very often") for both questionnaires, with the exception of assessment of global quality of life, which was evaluated in a seven-point scale. The questionnaires were filled in by all patients before and upon completion of radiotherapy. The specific sets of parameters were expressed in linearised scales from 0 to 100 , and a change of $\geq 10$ points was considered clinically significant [14]. The change of quality of life scales before and after radiotherapy were compared using the non-parametric statistical test for dependent data (sign test). It was assumed that there was a statistical significance at the level of $p$-value $<0.05$.

The results should be interpreted in accordance to the following rules:

- global quality of life - the more points, the higher the global quality of life,

- functional scales - the more points, the higher the quality of life in a particular scale,

- symptomatic scales - the more points, the more severe the symptoms.

In the last step we also compared the changes in quality of life among patients irradiated to the pelvic lymph nodes and those with prostate only irradiation.

\section{Results}

All 180 patients in the study group filled in the questionnaires. Compliance to answers in almost all scales was $100 \%$, except for the bowel scale on PR-25 (95\%) and the sexual activity or sexual functions scale $(89 \%$ and $15 \%$, respectively).

The quality of life scores before and after radiotherapy for those scales in which the change was statistically significant (10/21, 50\%) is presented in Table 2. Among them only the changes in diarrhoea and urinary symptoms were clinically significant (increase $\geq 10$ points).

A detailed distribution of the intensity of urinary symptoms before and after radiotherapy in a linearised scale from 0 to 100 is presented in Fig. 1. The intensity of polyuria, nycturia and pain accompanying micturition has commonly increased during radiotherapy (Table 3). Around three-quarters of patients did not complain of diarrhoea or loose stools before treatment, but these symptoms were present in half of the study group at the end of radiotherapy.

Almost $90 \%$ of patients answered the questions concerning their activity and interest in sexual life before and after radiotherapy, which allowed us to assess sexual ac- 
Table 2. Quality of life in QLQ-C30 and QLQ-PR25 modules for scales that reached a level of statistical significance $(p<0.05)$

\begin{tabular}{|c|c|c|c|c|}
\hline Scale: & $\begin{array}{c}\text { Score } \\
\text { before RT } \\
\text { (average) }\end{array}$ & $\begin{array}{c}\text { Score } \\
\text { after RT } \\
\text { (average) }\end{array}$ & Change & $p$-value \\
\hline \multicolumn{5}{|l|}{ Global quality of life (QLQ-C30): } \\
\hline Global quality of life & 61 & 57 & -4 & 0.03 \\
\hline \multicolumn{5}{|l|}{ Functional scales (QLQ-C30): } \\
\hline Physical functioning & 83 & 80 & -3 & 0.02 \\
\hline Social functioning & 87 & 82 & -5 & 0.006 \\
\hline \multicolumn{5}{|l|}{ Symptomatic scales (QLQ-C30): } \\
\hline Loss of appetite & 6 & 10 & 4 & 0.004 \\
\hline Constipation & 21 & 24 & 3 & 0.03 \\
\hline Diarrhoea & 10 & 20 & 10 & 0.00 \\
\hline \multicolumn{5}{|l|}{ Symptomatic and functional scales (QLQ-PR25): } \\
\hline Sexual activity & 27 & 18 & 9 & 0.0001 \\
\hline Urinary symptoms & 24 & 37 & 13 & 0.00 \\
\hline Bowel symptoms & 9 & 13 & 4 & 0.0001 \\
\hline Symptoms associated with hormonal treatment & 20 & 23 & 3 & 0.003 \\
\hline
\end{tabular}

Table 3. The distribution of answers to questions about specific symptoms that changed during radiotherapy (RT), with statistical significance

\begin{tabular}{|c|c|c|c|c|c|c|c|c|}
\hline \multirow[t]{2}{*}{ Parameter } & \multicolumn{4}{|c|}{$\begin{array}{c}\text { Before RT } \\
\text { answers }\end{array}$} & \multicolumn{4}{|c|}{$\begin{array}{l}\text { After RT } \\
\text { answers }\end{array}$} \\
\hline & Never & Sometimes & Often & Very often & Never & Sometimes & Often & Very often \\
\hline Polyuria & $12 \%$ & $43 \%$ & $37 \%$ & $8 \%$ & $2 \%$ & $32 \%$ & $50 \%$ & $16 \%$ \\
\hline Nocturia & $15 \%$ & $42 \%$ & $34 \%$ & $9 \%$ & $4 \%$ & $28 \%$ & $52 \%$ & $16 \%$ \\
\hline Urinary incontinence & $70 \%$ & $22 \%$ & $7 \%$ & $1 \%$ & $60 \%$ & $33 \%$ & $6 \%$ & $1 \%$ \\
\hline Pain during urination & $84 \%$ & $15 \%$ & $1 \%$ & $0 \%$ & $36 \%$ & $48 \%$ & $13 \%$ & $3 \%$ \\
\hline Interest in sex & $28 \%$ & $54 \%$ & $11 \%$ & $7 \%$ & $49 \%$ & $40 \%$ & $9 \%$ & $2 \%$ \\
\hline Sexual activity & $54 \%$ & $35 \%$ & $5 \%$ & $6 \%$ & $67 \%$ & $28 \%$ & $4 \%$ & $1 \%$ \\
\hline Constipation & $56 \%$ & $31 \%$ & $8 \%$ & $5 \%$ & $48 \%$ & $37 \%$ & $12 \%$ & $3 \%$ \\
\hline Diarrhoea & $73 \%$ & $25 \%$ & $1 \%$ & $1 \%$ & $51 \%$ & $39 \%$ & $11 \%$ & $0 \%$ \\
\hline
\end{tabular}

tivity (Table 3). However, the detailed set of questions on sexual life before and after radiotherapy were answered by only 27 patients, representing 15\% of the study group, so it was not possible to make a reliable analysis of the quality of sexual life.

A comparison of the quality of life among the patients treated with elective irradiation of the pelvic lymph nodes or irradiation of the prostate alone showed statistically significant differences in the severity of constipation and diarrhoea, but only the change in the severity of diarrhoea during radiotherapy achieved a clinically significant value. In the group with prostate only irradiation a small increase in diarrhoea was observed (from 9 to 15 points), while in the group with additionally irradiated pelvic lymph nodes its incidence was clinically significant (from 10 to 28 points).

\section{Discussion}

The compliance in our study was excellent. Apart from questions concerning sexual matters, non responses were

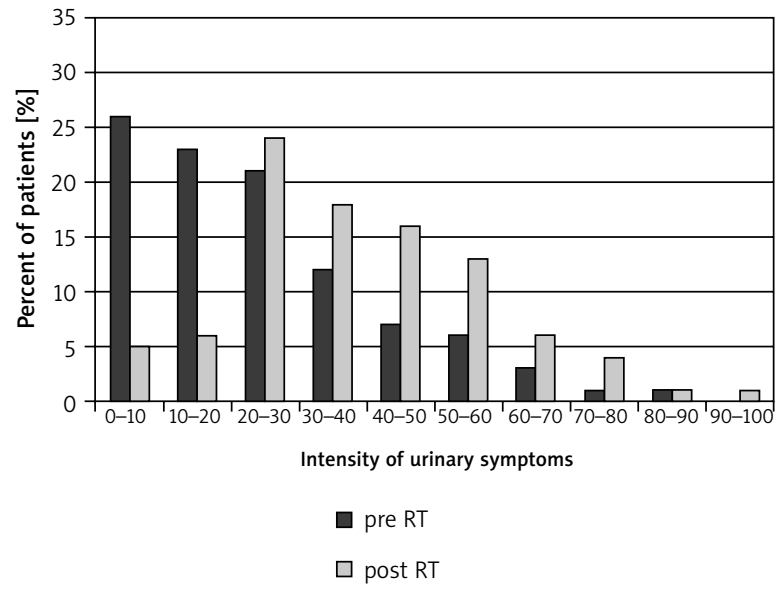

Fig. 1. The distribution of intensity of urinary symptoms before and after radiotherapy 
noted only regarding bowel function (PR-25), which were caused by misinterpretation of preceding question; however, this was controlled later in the study. The results of this study suggest a negligible impact of high-dose radiation therapy of prostate cancer on patients' quality of life. Clinically significant exacerbation of symptoms (more than 10 points) was observed only for urinary symptoms and diarrhoea, but it should be noted that the severity of diarrhoea increased in a clinically relevant way only in patients who had electively irradiated pelvic lymph nodes. In this group the increase in the incidence of diarrhoea was 18 points (from 10 to 28). In a survey this can correspond with a shift in answers from "never" to "sometimes" or from "sometimes" to "often" in more than half of the study group. Although various criteria may be used to evaluate the importance of differences in QoL scales, from a practical and clinical point of view, only relatively marked differences will be of clinical importance. Slight changes in QoL during RT, although statistically significant, are not accompanied by the necessity of pharmacological treatment or other interventions and may be compared at most to slight Grade 1 radiation toxicity. Therefore, the criterion of a 10-point difference excluding small and irrelevant changes, as proposed by Osoba et al. [14], was considered appropriate in this study.

In 2006, a group from Toronto published results on quality of life in patients with prostate cancer recurrence after prostatectomy treated with radiotherapy (60-66 Gy) [15]. In the discussed material, overall severity of symptoms of bowel dysfunction increased by $28 \%$ after radiotherapy. In our study, the increase in bowel symptoms in a linearised scale was similar to that seen in the study by Geinitz et al. [4], i.e. only 4 points. This increase is negligible from a clinical point of view, but in relative values it is a change of about $40 \%$ compared to the score before radiotherapy. In the study by Nowicki et al. [16] bowel symptoms evolved slightly more (average point scale before and after RT: 1.17 and 1.47 , respectively, which gives, after linear transformation, a 10 point increase from 6 to 16 points). Studies dealing with long-term quality of life changes also show some impairment in bowel function, although it is usually of small magnitude $[3,5,8,10]$.

In terms of changes in the severity of diarrhoea, our own results are comparable to the observations of Lips et al. [7, 17], who noted in a group irradiated with use of IMRT technique a 7 point increase, comparable to 10 points in our study. The results of these investigators, however, differ from our results in terms of urinary symptoms. The cited authors did not show significant changes in urinary symptoms, which were emphasised in our study. However, in the group irradiated with 3D conformal techniques, those authors reported even greater increases in urinary symptoms than in our study (from 18 points to 34 points). This means that perhaps strictly conformal-dynamic techniques of radiotherapy (IMRT), limited only to the prostate gland, with precise fiducial-based positioning, can have a better effect on the tolerance of the bladder. Similarly to our findings, a deterioration of urinary function during or shortly after radiotherapy was observed also by other authors $[4,8,16]$, which is consistent with our previous clinical observations on acute radiation-induced reactions of the bladder [18]. Morton et al. [8] observed a two-fold increase in urinary symptoms (measured by an IPSS score) shortly after radiotherapy, with a rapid decline thereafter, indicating healing of acute toxicity.

The importance of pelvic lymph node irradiation for the deterioration of quality of life associated with symptoms from bowels (diarrhoea) is associated with a higher volume of irradiated bowel loops, and it seems to be logically explained. Such a relationship, as in the present study, was also observed by other authors $[5,19]$.

Radiotherapy in patients with prostate cancer in a long-term perspective does not have a serious adverse impact on quality of life $[3,6,7,9,10]$. However, during radiation therapy, the quality of life usually worsens, although mostly in a small and clinically insignificant way and only with respect to certain parameters, which was observed both in the present study and in other studies $[4,7,8,17,20]$. Some differences between specific aspects of the analyses in the studies are often the result of various patient populations and their different clinical characteristics.

Another point of discussion concerns the results pertaining to the sexual life of patients with prostate cancer. A small number of responses could be explained either by low sexual activity in the analysed age group, or by a reluctance to disclose intimate details of their sexual life. Curiously, some sexual activity (answer "sometimes") was declared before radiotherapy by $45 \%$ of patients who responded, while in the whole studied group almost $90 \%$ of patients received hormonal therapy. This fact casts doubts on the reliability of the patient's answers in this subject. A decrease in the quality of sexual life observed after radiation therapy is also described by other authors $[3,7,8,16,21]$. For example, researchers from Utrecht, in a group of patients with prostate cancer treated by IMRT, noticed clinically significant worsening of sexual activity (11 points during radiotherapy) continuing over the subsequent 3 years after the end of treatment, but with the group of 116 patients, questions about sexual activity were answered only by 32 patients [7]. A decrease in sexual activity may be associated with hormonal therapy; Sanda et al. drew attention to this issue in their study [21]. Therefore, in our opinion, making a reliable, comparative analysis of sexual function with such a small number of answers about the quality of sexual life in our own material (in which hormone therapy was used in approximately $90 \%$ of cases) could be charged with a considerable estimation bias.

In conclusion, in general, the quality of life in patients with prostate cancer treated with image-guided radiotherapy does not change significantly during radiotherapy, which corroborates good treatment tolerance. A significant increase in urinary symptoms and, in the case of elective pelvic irradiation, also an increase in diarrhoea have a negative impact on symptom-related quality of life.

The authors declare no conflict of interest. 


\section{References}

1. Kulik A, Dąbkowski M. Prostate cancer radiotherapy. Contemp Oncol (Pozn) 2011; 15: 317-22.

2. Jereczek-Fossa BA. Rola radioterapii w leczeniu raka gruczołu krokowego. Contemp Oncol (Pozn) 2003; 7: 176-82.

3. Jereczek Fossa BA, Santoro L, Zerini D, et al. Image guided hypof ractionated radiotherapy and quality of life for localized prostate cancer: prospective longitudinal study in 337 patients. J Urol 2013; 189: 2099-103.

4. Geinitz H, Thamm R, Scholz C, et al. Longitudinal analysis of quality of life in patients receiving conformal radiation therapy for prostate cancer. Strahlenther Oncol 2010; 186: 46-52.

5. Hanlon AL, Watkins Bruner D, Peter R, Hanks GE. Quality of life study in prostate cancer patients treated with three-dimensiona conformal radiation therapy: comparing late bowel and bladder symptoms to that of the normal population. Int J Radiat Oncol Biol Phys 2001; 49: 51-9.

6. Hoskin PJ, Rojas AM, Ostler PJ, Hughes R, Lowe GJ, Bryant L. Quality of life after radical radiotherapy for prostate cancer: longitudinal study from a randomized trial of external beam radiotherapy alone or in combination with high dose rate brachytherapy. Clin Oncol (R Coll Radiol) 2013; 25: 321-7.

7. Lips IM, van Gils CH, van der Heide UA, Kruger AE, van Vulpen $M$. Health-related quality of life 3 years after high-dose intensity-modulated radiotherapy with gold fiducial marker-based position verification. BJU Int 2009; 103: 762-7.

8. Morton GC, Loblaw DA, Sankreacha R, et al. Single-fraction highdose-rate brachytherapy and hypofractionated external beam radiotherapy for men with intermediate-risk prostate cancer: analysis of short- and medium-toxicity and quality of life. Int J Radiat Oncol Biol Phys 2010; 77: 811-7.

9. Pommier P, Chabaud S, Lagrange JL, et al. Is there a role for pelvic irradiation in localized prostate adenocarcinoma? Preliminary results of GETUG-01. J Clin Oncol 2007; 25: 5366-73.

10. Schaake W, de Groot M, Krijnen WP, Langendijk JA, van den Bergh AC. Quality of life among prostate cancer patients: A prospective longitudinal population-based study. Radiother Oncol 2013; 108: 299-305.

11. D'Amico AV, Whittington R, Malkowicz SB, et al. Biochemical outcome after radical prostatectomy, external beam radiation therapy, or interstitial radiation therapy for clinically localized prostate cancer. JAMA 1998; 280: 969-74.

12. Aaronson NK, Ahmedzai S, Bergman B, et al. The European Organization for Research and Treatment of Cancer QLQ-C30: A quality-of-life instrument for use in international clinical trials in oncology. J Natl Cancer Inst 1993; 85: 365-76.

13. van Andel G, Bottomley A, Fossa SD, et al. An international field study of the EORTC QLQ-PR25: a questionnaire for assessing health-related quality of life of patients with prostate cancer. Eur J Cancer 2008; 44: 2418-24.

14. Osoba D, Rodrigues G, Myles J, Zee B, Pater J. Interpreting the significance of changes in health-related quality-of-life scores. J Clin Oncol 1998; 16: 139-44.

15. Pearce A, Choo R, Danjoux C, Morton G, Loblaw DA, Szumacher E, Cheung P, Deboer G, Chander S. Int J Radiat Oncol Biol Phys 2006; 65: 78-83.

16. Nowicki A, Staniewska J, Tesmer I. Ocena jakości życia chorych na raka gruczołu krokowego hospitalizowanych w trakcie radioterapii radykalnej. Część II. Contemp Oncol (Pozn) 2007; 11: 449-54.

17. Lips I, Dehnad H, Kruger AB, van Moorselaar J, van der Heide U, Battermann J, van Vulpen M. Health-related quality of life in patients with locally advanced prostate cancer after 76 Gy intensity-modulated radiotherapy vs. 70 Gy conformal radiotherapy in a prospective and longitudinal study. Int J Radiat Oncol Biol Phys 2007; 69: 656-61.

18. Majewski W, Prokop E, Tabor K, Kulik R. Ocena wczesnej tolerancji radioterapii kierowanej obrazowaniem (IGRT) u chorych na raka gruczołu krokowego. Onkologia Info 2011; 2: 37-44.

19. Pinkawa M, Piroth MD, Holy R, Fischedick K, Klotz J, Székely-Orbán D, Eble MJ. Quality of life after whole pelvic versus prostate-only external beam radiotherapy for prostste cancer: a matched-pair comparison. Int J Radiat Oncol Biol Phys 2011; 81: 23-8.
20. Janda M, Gerstner N, Obermair A, Fuerst A, Wachter S, Dieckmann K, Pötter R. Quality of life changes during conformal radiation therapy for prostate carcinoma. Cancer 2000; 89: 1322-8.

21. Sanda MG, Dunn RL, Michalski J, et al. Quality of life and satisfaction with outcome among prostate-cancer survivors. N Engl J Med 2008; 358: 1250-61.

\section{Address for correspondence}

Wojciech Majewski MD, PhD

Department of Radiotherapy

Centrum Onkologii Instytut im. Marii Skłodowskiej-Curie,

Oddział w Gliwicach

Wybrzeże Armii Krajowej 15

44-100 Gliwice, Poland

tel. +4832278 8001

e-mail: wmajewski1@poczta.onet.pl

Submitted: 24.06 .2013

Accepted: $\quad 13.11 .2013$ 